\title{
Determining consumption preferences of consumers considering quality attributes
}

\section{of drinking water: case of Iğdır}

\author{
Emine Aşkan ${ }^{1, *}$, Yavuz Topcu ${ }^{2}$, Ayça Nur Şahin ${ }^{1}$ \\ ${ }^{1}$ Department of Agricultural Economics, College of Agriculture, I $\breve{g d i r}$ University, Iğdır, Turkey; ${ }^{2}$ Department of Agricultural \\ Economics, College of Agriculture, Ataturk University, Erzurum, Turkey
}

*Corresponding Author: Emine Aşkan, Department of Agricultural Economics, College of Agriculture, Iğdır University, Iğdır, Turkey, Email: emine.askan@igdir.edu.tr

Received: 22 March 2021; Accepted: 15 July 2021; Published: 9 August 2021

(c) 2021 Codon Publications

OPEN ACCESS (C) (1) (2)(2)

PAPER

\begin{abstract}
The aim of the study was to determine the main factors affecting the consumption preferences of consumers by considering the quality characteristics of drinking water according to the regions where they reside. For this purpose, the data obtained from 400 consumers living in the central districts of Iğdır province were used for Factor Analysis and Two-Step Clustering Analysis. Research results reported that physiological needs of the consumers residing in region I were based on the physiological and physical quality of the water in their drinking water consumption preference, consumers in region II relied on the chemical quality of the tap water, and consumers in region III focused on the cost advantages of tap water depending on the chemical quality of tap water. Therefore, supplying differentiated bottled drinking water in hygienic conditions according to physical and physiological quality standards of drinking water for consumers in region I, ensuring the protection and access of local water resources suitable for chemical quality characteristics to consumers in region II, and maintaining the reliability of local water resources with good chemical quality and low cost of supply and sustainability of their use for consumers in region III can have positive effects on consumption satisfaction.
\end{abstract}

Keywords: drinking water consumption; factor analysis; two-step cluster analysis; water quality

\section{Introduction}

Water is one of the most important natural resources for all living creatures that have no substitute as a natural resource. It is the second most important indispensable component after oxygen for the existence of human life on earth. Oceans and seas make up $97.5 \%$ of the world's water, while $2.5 \%$ is fresh water. About $87 \%$ of fresh water cannot be used without treatment (Yllmaz and Peker, 2013).

Water resources are scarce and the world population which constantly demands these resources is increasing rapidly. In addition, industrialization weakens the sustainability of natural resources and makes it difficult for people to access safe drinking water (Tanellari et al., 2015). Organizations such as the United Nations World Water Council (UNCWW), the World Resources Institute (IWR), and the World Health Organization (WHO) stated that in the 1950s, only a few countries had water problems; in the 1990s, 26 countries with 300 million people suffered from thirst; and by 2050, there will be severe water shortage in 66 countries where $2 / 3$ of the world's population lives (Anonymous, 2015).

On the other hand, the recent global climate changes and global warming, as well as the developments in mining and waste recycling technologies, significantly reduce and pollute both the water resources used for agricultural purposes and the water supply resources 
available to people. When countries are classified according to water availability, countries with less than $1000 \mathrm{~m}^{3}$ of usable water per capita per year are considered "water poor, countries with less than $2000 \mathrm{~m}^{3}$ of water are considered "water scarce," and countries with more than $8000-10,000 \mathrm{~m}^{3}$ are considered "water rich" (DPT, 2007). According to the world average, usable annual amount of water per person is $7.600 \mathrm{~m}^{3}$ (Anonymous, 2015). Turkey is seen as a country that suffers from water scarcity when approximately $1.519 \mathrm{~m}^{3}$ of usable fresh water per person is taken into account. The total amount of usable water in Turkey is around 112 billion $\mathrm{m}^{3}$. The amount of water per person per day for drinking and use in Turkey is 216 L (TUIK, 2020). The water footprint of an individual, society, or line of business is the total amount of clean water resources used for the production of goods and services consumed by the individual or society, or used by the producer for the production of goods and services. According to the water footprint approach, it is stated that the daily direct and indirect water consumption of a person in Turkey is 5416 L (WWF Report, 2014).

The rapid increase in both the number and population of cities in Turkey has made it difficult to meet the water needs of the cities only from available sources and groundwater. For this reason, the water needs of rapidly growing cities are tried to be met by purification from rivers, dams, and lakes, as well as spring and groundwater (Özgüler, 1997). It may be possible that the water is supplied from an unhealthy source or the water transferred from a healthy water source is exposed to various microbiological contaminants before reaching the consumer. On the other hand, both natural resource destruction with chemical pesticides and genetic modifications, and improper practices in mining operations as well as factory waste and polluted air emissions cause intensive pollution of the environment and groundwater resources. It is imperative that these contaminated water resources reach usable drinking and utility water standards in terms of chemical, physical, and microbiological water quality (Li and Wu, 2019; Liu et al., 2017; Zlatanovic et al., 2017). The process of distillation and purification of heavily polluted drinking water with various technological approaches and the grading of drinking water with various quality characteristics and its presentation to consumers are of great importance. Limit values of usable fresh water are determined according to hygiene, toxic, technical, and aesthetic criteria. In addition, heavy metals, calcium, magnesium, and nitrate values must be reached to levels that will not harm human health (Kılıç, 2008).

Wells were drilled in the shallow aquifer $(6-10 \mathrm{~m})$ and in the deep aquifer during the studies carried out to obtain information about the groundwater in the Iğdır
Plain. In all wells drilled in a shallow aquifer, the EC and total salt values are above the permissible values. In addition, most of them have $\mathrm{Ca}, \mathrm{Mg}, \mathrm{SO}_{4}, \mathrm{Cl}$, and hardness values above the permissible values. For this reason, shallow well waters were not found suitable for drinking, and chemical heavy metal analyzes are carried out by regularly taking water samples from Gaziler, Acıçay, Hamurkesen, Yazlık Village, Gürgöre, and Hıdırlı spring waters in the Iğdır province. Although there are no pollutants in the mentioned water resources, considering the heavy metal contents of the sources other than the Hamurkesen spring, they were not found suitable to be used as drinking and utility water. Therefore, this research area constitutes a rare micro-area used as drinking water in terms of underground resources in Turkey and is immediately accepted as the only sampling region at the national level (Anonymous, 2015).

Due to all these negative reasons, people living in Iğdır are trying to make the water usable safely by using personal purifiers in both apartments and houses in order to use the city tap water. However, various spring waters, which have a very high usage area, are far from meeting the needs of consumers, by means of purifiers. For this reason, consumers use well water as drinking water without objective measurements regarding the usability and safety of water as drinking water according to usable quality criteria. In addition to this, initiatives for ready water supply also constitute a very important domestic market in Iğdır. In this case, consumers, who have to meet their water consumption needs, exhibit different attitudes and behaviors in terms of their residential areas, taking into account the effects of both water resources and drinking water on health.

When the factors affecting the water consumption of consumers are examined, the number of households, the behavior of the consumers, the existence of the garden and swimming pool of the household, and the plant type in the garden are reported as important factors. At the same time, it has been determined that in regions where water scarcity is experienced, besides water price and income, social and demographic characteristics of consumers are effective (Domene and Saurí, 2007). In addition, it has been analyzed that body weight and temperature and physical activities have an effect on water consumption rates (Şen and Altunkaynak, 2009). In the study conducted by Arslan and Mendeş in 2004, it was reported that gender did not affect water consumption and that there was no conscious water consumption in the society (Arslan and Mendeş, 2004). Milton et al. (2006) reported that drinking water is exposed to various pollutants (such as arsenic, lime, and metal-based minerals), making it difficult to access healthy water supply sources, and therefore the amount of drinking water consumption is significantly reduced. 
Consumers who believe that the drinking water provided by the local and administrative administrations in Iğdır is not at a sufficient level in terms of purification from harmful substances, hygiene, quality, and reliability, integrates purification devices into the water lines within the residence, tends to use bottled drinking water, and turns to neighborhood fountains or well waters that they find reliable. Among the factors that determine the behavior of consumers towards these alternatives, factors such as physiological effect; chemical, physical, and microbiological quality of water; hygiene; safety of water; access to spring or tap water; physical quality and preservation of tap water; and reliability of drinking water distribution networks are of great importance (Dönderici et al., 2010; Li and Wu, 2019; Liu et al., 2017; Zlatanovic et al., 2017). Consumers residing in different regions of the province of Iğdır experience significant problems in accessing network, spring, and ready-made bottled drinking water with alternative usable physical and chemical quality. Therefore, in the research, the following question appears: Which quality characteristics determine the drinking water consumption of consumers residing in different regions of Iğdır province, ready-made water, tap water, tap water connected to the purification device, or spring (fountain) water? In addition to answering the question, this research has been planned in order to help local and administrative administrations and water supply retailers create strategic plans for target audiences.

\section{Materials and Methods}

\section{Material}

The primary data of the study were obtained from faceto-face surveys conducted with households residing in the city center of Iğdır in 2019 (Table 1). On the other hand, secondary data obtained from the various domestic and foreign researches and reports, from the public institutions and organizations such as Turkey Statistics Institution (TSI) and FAO, and Iğdir municipality and governorship records were also used.

\section{Method}

\section{Sampling method}

Taking into account the 2018 Address Based Population Registration System (ADNKS), it was determined that the central population of Iğdır was 137.613 people (TURKSTAT, 2019), which was accepted as the main population. The sample size, which takes into account the probability of the population, whose main population has been determined, to benefit from the local drinking water source, was calculated using the Simple Random Sampling Method Based on Population Proportions, with the help of following equation (Newbold, 1995; Şahin, 2019).

$$
\mathrm{n}=\frac{\mathrm{N}_{\mathrm{p}}(1-\mathrm{p})}{(\mathrm{N}-1) \sigma_{\mathrm{p}}^{2}+\mathrm{p}(1-\mathrm{p})}
$$

In equation;

n: Sample size,

$\mathrm{N}$ : Iğdır city center population (person),

$r$ : Deviation from the mean (margin of error) (5\%),

$\mathrm{Z}_{\alpha / 2}: \mathrm{Z}$ table value (1.96),

$\mathrm{p}$ : The proportion of those who prefer tap drinking water $(50 \%)$,

$\sigma_{\mathrm{p}}^{2}$ : Major population variance.

$$
\sigma_{\mathrm{p}}^{2}=\left(\frac{\mathrm{r}}{\mathrm{Z}_{\alpha / 2}}\right)^{2}=\left(\frac{0.05}{1.96}\right)^{2}=(0.0255)^{2}
$$

It is calculated as,

$$
\mathrm{n}=\frac{137613 \times 0.5 \times 0.5}{\left(137612 \times(0.0255)^{2}\right)+(0.5 \times 0.5)}=384 \text { consumers }
$$

In order to reach the maximum sample volume in the study, p: 0.50 and q: 0.50 were taken. On the other hand, taking into account the number of people in the neighborhoods to be surveyed in each region, how many surveys will be conducted in which neighborhoods with proportional method was determined and given in Table 1.

During data collection, face-to-face interviews were conducted with 404 consumers by increasing the number of questionnaires by $5 \%$ in order to compensate for errors caused by the respondent or the researcher. While counting and cleaning the survey data, the questionnaires containing incorrect and missing data were removed from the data set and the survey data of 400 consumers in total were coded and made ready for analysis in the digital environment.

\section{Methods used in the preparation of the questionnaires}

Participants of the survey were asked to respond to each statement indicating the significance level of their drinking water consumption preferences. A Likert-type scale was used (where 1 refers to the least important attribute, and 5 refers to the most important attributes). The questions related to the drinking water consumption preferences of the consumers consisted of 52 variables belonging to main factors such as physiological, physical, and chemical quality attributes, confidence, and advantages of tap water (Table 2). On the other hand, the questions with open and closed-ended scale types for the socioeconomic and demographic factors influencing their drinking water consumption preferences were used (Table 3 and Table 4). 
Table 1. Number of surveys conducted in the neighborhoods of Iğdır city center.

\begin{tabular}{lc} 
Name of the neighborhood & Number of surveys \\
\hline 14 Kasım neighborhood & 28 \\
Ali Kamerli neighborhood & 9 \\
Atatürk neighborhood & 14 \\
Bağlar neighborhood & 50 \\
Cumhuriyet neighborhood & 23 \\
Emek neighborhood & 36 \\
Hakveyis neighborhood & 4 \\
Karaağaç neighborhood & 30 \\
Konaklı neighborhood & 24 \\
Özgür neighborhood & 42 \\
Pir Sultan Abdal neighborhood & 17 \\
Söğütlü neighborhood & 27 \\
Topcular neighborhood & 37 \\
Yeni neighborhood & 6 \\
Bahçelievler neighborhood & 5 \\
Özvatan neighborhood & 6 \\
Said Nursi neighborhood & 4 \\
Turgut Özal neighborhood & 7 \\
Yunus Emre neighborhood & 4 \\
Faruktoka neighborhood & 4 \\
Yeni neighborhood & 8 \\
Güneşli neighborhood & 4 \\
Mehmet Akif Ersoy neighborhood & 4 \\
Namık Kemal neighborhood & 4 \\
Total number of surveys & 4 \\
\hline & 4 \\
\hline
\end{tabular}

\section{Methods used in the statistics analyses}

After editing and coding, factor analysis (FA) was first used to determine the main factors related to the product attitudes affecting the consumers' drinking water consumption preferences and purchase patterns. FA is a data technique that reduces the number of variables used in analysis by creating new factors that combine redundancy in the data (Kurtuluş, 2004; SPSS, 20.0, 2020; Tekin, 2007). The first step in FA is to determine the number of relevant factors. This was conducted by FA using the Varimax Rotation Method under an orthogonal rotation method minimizing the number of variables that have high loading on each factor (Karagöz, 2017; Karpati and Szakal, 2009). FA was used initially to identify the underlying aspect explaining a correlation among a set of the drinking water attributes. The purpose of FA was to identify those attributes accounting for a relatively large proportion of the variance in the sample.

In the second step of the statistical analyses, the main factors obtained from FA were used for two-step cluster analysis. Two-step cluster analysis, which gives the ideal number of clusters between the factors obtained and the consumption groups desired to be formed, is the most effective clustering technique (Doğan, 2008; Özdamar, 2004; S Sekerler, 2008; Topcu and Baran, 2017). In the present study, therefore, the target consumers were separated to three homogenous clusters as regions I, II, and III by considering the relationships between the main factors obtained from FA and the location of the neighborhoods according to the distances to city center where the consumers who prefer clean drinking water resided in Iğdır Province.

In the final step of the statistical analysis, descriptive statistics such as compare means, crosstabs, descriptive and frequencies were used to determine demographic and socioeconomic profiles of three consumer clusters segmented by two-step cluster analysis.

All analyses were run in sequence with the SPSS 20.0 statistical software. These techniques were frequently used to analyze the product attributes playing the important roles on the consumers' consumption preferences in marketing studies (Drugova et al., 2020; Egbueri et al., 2020; Harwood et al., 2020; Kusa et al., 2020; Topcu, 2006; Topcu and Baran, 2017).

\section{Results and Discussion}

\section{The results of FA related to consumers' drinking water consumption preferences}

Kaiser Normalization (KMO), which compares the observation and partial correlation coefficients, including the consumers' attitudes and behavior towards drinking water consumption preferences, was calculated as 0.723 . On the other hand, Bartlett's Sphericity test statistics was calculated as $2529.433(\mathrm{P}=0.000)$. These two statistics evaluating the sample data showed that the data related to the factors affecting the consumers' drinking water consumption preferences was at a good level for FA.

Of the 52 variables, 33 were excluded from the data set, and 19 variables were used in FA. Because the 33 variables had not the sufficient loads to explain the common variance, overlap and factor dimensions on the consumers' drinking water consumption preferences. Considering Eigen-values greater than 1 and the explanatory variance rates in the factor dimensions created by 19 variables effecting their preferences, 5 main factors were obtained, which explained approximately $62 \%$ of the total variance (Table 2).

Physiological quality of water as the first preference factor explained $15.72 \%$ of the total variance. It indicated that people should drink at least $2 \mathrm{~L}$ water a day 
Table 2. The results of FA and fit statistics

Factor interpretations and variables

\section{Factor and variable loads*}

$\begin{array}{llll}\text { F1 } & \text { F2 } & \text { F3 } & \text { F4 }\end{array}$

F4

F5

\section{Physiological quality of water}

Effect of water on digestion

Drinking water aids weight loss and enhances skin

Physiological functions of water in the body

Drinking water removes toxins and cleanses the blood

At least $2 \mathrm{~L}$ water should be consumed daily for health.

Men and women should daily drink 3 and $2.5 \mathrm{~L}$ water, respectively

Physical quality of water

Muddy water after tap water outage

Purified water tastes better and doesn't contain harmful chemicals.

Packaged waters are clearer and cleaner

Tap water is sometimes yellow and smells bad

\section{Confidence in tap water}

We purify the tap water and drink it more safely

Purified water is much healthier than bottled water

Purified tap water tastes more pleasant

Chemical quality of water

The amount of calcium in quality water is close to $250 \mathrm{mg}$

The amount of magnesium in quality water is close to $75 \mathrm{mg}$

The $\mathrm{PH}$ of treated water is basic

\section{Advantage of tap water}

Low cost and availability of tap water

The fact that the tap water is cold in summer and winter

Transfer difficulty of tap water

\begin{tabular}{|c|c|c|c|c|}
\hline 0.786 & 0.102 & -0.023 & 0.011 & 0.011 \\
\hline 0.786 & 0.087 & -0.035 & -0.013 & 0.049 \\
\hline 0.782 & 0.064 & -0.021 & -0.030 & 0.079 \\
\hline 0.659 & 0.039 & 0.124 & 0.021 & -0.022 \\
\hline 0.573 & 0.019 & -0.032 & 0.003 & 0.153 \\
\hline 0.558 & 0.033 & -0.014 & 0.019 & 0.005 \\
\hline 0.068 & 0.773 & -0.002 & -0.046 & 0.034 \\
\hline 0.080 & 0.725 & -0.304 & -0.191 & 0.079 \\
\hline 0.118 & 0.707 & -0.111 & -0.142 & 0.123 \\
\hline 0.049 & 0.700 & 0.074 & 0.129 & -0.005 \\
\hline-0.039 & -0.038 & 0.875 & -0.026 & -0.123 \\
\hline 0.016 & -0.090 & 0.817 & -0.011 & -0.034 \\
\hline 0.032 & -0.063 & 0.786 & -0.084 & 0.008 \\
\hline 0.012 & -0.198 & -0.005 & 0.881 & 0.100 \\
\hline-0.074 & -0.234 & 0.041 & 0.855 & 0.156 \\
\hline 0.083 & 0.290 & -0.201 & 0.672 & 0.029 \\
\hline 0.094 & -0.016 & -0.072 & 0.094 & 0.876 \\
\hline 0.031 & 0.033 & -0.024 & -0.011 & 0.865 \\
\hline 0.116 & 0.201 & -0.055 & 0.193 & 0.656 \\
\hline 2.987 & 2.370 & 2.230 & 2.090 & 2.051 \\
\hline 15.719 & 12.475 & 11.737 & 10.999 & 10.796 \\
\hline 15.719 & 28.194 & 39.932 & 50.931 & 61.727 \\
\hline \multicolumn{5}{|c|}{$\begin{array}{l}0.723 \\
\left.\text { [Chi-square }\left(\lambda_{2 \mathrm{df}}: 171\right): 2529.43\right](P=0.000) \\
400\end{array}$} \\
\hline
\end{tabular}

\section{Factorization statistics}

Eigen-value

Explained variance (\%)

Cumulative explained variance (\%)

\section{Fit statistics}

KMO (Kaiser-Meyer-Olkin) statistic

Bartlett's test of sphericity

Number of samples $(n)$

"Bold numbers indicate the largest loading for each variable for a healthy and balanced diet, because water helps the digestive system to work better and cleans the blood by removing harmful chemicals and toxins from the body, is the main substance and vitality source in all physiological functions in the body, makes the skin beautiful, and helps people to lose weight. Previous researches, therefore, declared that men and women should drink 3 and $2.5 \mathrm{~L}$ water, respectively (Cuvelier and Bartell, 2021; İbrahim et al., 2021). Explaining the physiological effects of drinking water on human health in all its dimensions, Mukate et al. (2019) evaluated the direct and indirect effects of various problems of unsuitable drinking of water in human physiology with many dimensions.

On the other hand, water's physical quality as the second factor explained $12.48 \%$ of the total variance. It consisted of variables such as the water provided by the treatment processes not affecting drinking water's chemical quality, the packaged water from the source, the tap water's turbid flow, and sometimes being yellowish after being interrupted and not being as pure and clean as it appeared (Table 2). The consumers, therefore, gave much 
Table 3. Final cluster center scores and sample numbers in each cluster

\begin{tabular}{|c|c|c|c|}
\hline \multirow[t]{2}{*}{ Main factors } & \multicolumn{3}{|c|}{ Drinking water consumption preference groups* } \\
\hline & Region I & Region II & Region III \\
\hline Physiological quality of water & $0.08^{* * *}$ & $0.06^{* * *}$ & $-0.17^{\star * *}$ \\
\hline Physical quality of water & $0.26^{* * *}$ & $-0.08^{* * *}$ & $0.03^{* * *}$ \\
\hline Confidence in tap water & $-0.11^{* * *}$ & $0.07^{* * *}$ & $-0.05^{+* *+}$ \\
\hline Chemical quality of water & $-0.12^{* * *}$ & $0.09^{* * *}$ & $0.07^{* * *}$ \\
\hline Advantage of tap water & $-0.01^{* * *}$ & $-0.06^{* * *}$ & $0.08^{\star * *}$ \\
\hline Number of samples in each segment & 148 & 132 & 120 \\
\hline Sample percent in each cluster (\%) & 37 & 33 & 30 \\
\hline
\end{tabular}

Table 4. Demographic and socioeconomic characteristics of the participants in each cluster.

\begin{tabular}{|c|c|c|c|c|c|}
\hline \multicolumn{2}{|c|}{ Demographic and socioeconomic factors } & \multicolumn{3}{|c|}{ Drinking water consumption preference groups } & \multirow[t]{2}{*}{ Total } \\
\hline & & Region I & Region II & Region III & \\
\hline \multirow[t]{2}{*}{ Gender } & Male & 57 & 66 & 74 & 197 \\
\hline & Female & 63 & 66 & 74 & 203 \\
\hline \multirow[t]{5}{*}{ Occupation } & White-collar & 36 & 35 & 44 & 115 \\
\hline & Worker & 23 & 24 & 18 & 65 \\
\hline & Self-employment & 6 & 10 & 14 & 30 \\
\hline & Housewife & 28 & 27 & 26 & 81 \\
\hline & Student & 15 & 19 & 19 & 53 \\
\hline \multirow[t]{3}{*}{ Household (person) } & Mean & 4.06 & 3.93 & 3.90 & 3.96 \\
\hline & $n$ & 120 & 132 & 148 & 400 \\
\hline & Std. Deviation & 1590 & 1514 & 1446 & 1512 \\
\hline \multirow[t]{3}{*}{ Age (year) } & Mean & 37.52 & 34.27 & 37.71 & 36.51 \\
\hline & $n$ & 120 & 132 & 148 & 400 \\
\hline & Std. Deviation & 15.13 & 13.06 & 14.06 & 14.13 \\
\hline \multirow[t]{3}{*}{ Education (year) } & Mean & 10.58 & 11.05 & 11.21 & 10.97 \\
\hline & $n$ & 120 & 132 & 148 & 400 \\
\hline & Std. Deviation & 4415 & 4136 & 4355 & 4299 \\
\hline \multirow[t]{3}{*}{ Income (TL) } & Mean & 4295.59 & 4218.03 & 4697.01 & 4418.52 \\
\hline & $n$ & 120 & 132 & 148 & 400 \\
\hline & Std. Deviation & 2226.88 & 2096.33 & 2411.85 & 2260.86 \\
\hline \multirow[t]{3}{*}{ Food expenditure (TL) } & Mean & 672.92 & 645.83 & 659.32 & 658.95 \\
\hline & $n$ & 120 & 132 & 148 & 400 \\
\hline & Std. Deviation & 265.52 & 296.61 & 268.76 & 276.84 \\
\hline \multirow[t]{3}{*}{ Total expenditure (TL) } & Mean & 2389.04 & 2333.63 & 2417.74 & 2381.37 \\
\hline & $n$ & 120 & 132 & 148 & 400 \\
\hline & Std. Deviation & 1020.85 & 1000.31 & 927.38 & 978.50 \\
\hline \multirow[t]{3}{*}{ Water consumption (liters) } & Mean & 7.13 & 7.39 & 7.47 & 734 \\
\hline & $n$ & 120 & 132 & 148 & 400 \\
\hline & Std. Deviation & 2631 & 2.48 & 2428 & 2505 \\
\hline
\end{tabular}

"Bold numbers indicate the highest socioeconomic and demographic variable values and frequencies 
importance to drinking water hygiene. Similar to these results, it was been reported that hygiene was an important factor in the consumption of packaged and purified drinking water in India (Suganthi, 2014). In addition, it was pointed out that quality attributes such as taste and flavor, smell, clarity, and hygiene revealing the consumers' drinking water preferences was similar to the results found by Tümer et al. (2011) and Doria (2006).

The third factor explaining $11.74 \%$ of the total variance represented confidence in tap water. The factor covered in the variables such as city tap water preserving through treatment, and believing being safer than alternative drinking water supply sources. Pointing to the issue of treating the tap water in various ways and supplying it through reliable and healthy distribution systems, Liu et al. (2017) and Zlatanovic et al. (2017) highlighted that the water source and network distribution systems and their elements were effective on the physiochemical and microbiological quality of water.

The chemical quality of water, the fourth preference factor, explained $10.99 \%$ of the total variance. Good-quality potable water should include $250 \mathrm{mg}$ calcium and $75 \mathrm{mg}$ magnesium per liter; however, not only these ratios but also the PH levels for treated drinking water were lower. Similarly, the research conducted by $\mathrm{Li}$ and Wu (2019) emphasized that continuity of standardized essential nutrients and mineral substance amounts in drinking water's chemical quality was of great importance and had major effects on public health. Dönderici et al. (2010) also reported that drinking water's physical and chemical quality attributes had great importance in order to determine potable water resources deteriorating under the effect of various environmental factors. On the other hand, the fifth preference factor under tap water advantage explained $10.80 \%$ of the total variance, and thus the biggest advantage of fountain water was of a drinkable temperature without a real purchase cost versus a remarkable transfer cost. Indeed, it does not require an effective cost by providing procurement cost advantage on the consumer demands due to the water being at a drinkable temperature and always accessible throughout all year. However, it could be exposed to significant problems through various storage and transport vehicles with various microbiological contaminations. Exploring these issues in detail, McGuinness et al. (2020) highlighted that transportation methods with closed systems from safe water sources should be investigated instead of using transportation and storage vehicles to be able to prevent various microbiological contaminants.

\section{The results of cluster analysis}

Target consumer masses were segmented to three homogenous groups such as regions I, II, and III by considering the relationships among five main factors based on the consumers' drinking water consumption preferences and their residence neighborhoods. The distributions of their five preference factors in each homogeneous cluster were given in Table 3 .

The ratios of the consumers residing in regions I, II, and III of Iğdır province were determined as 37\% (148 households), 33\% (132 households), and 30\% (120 households), respectively (Figure 1).

The consumers residing in region I shaped the purchasing models responding to their physiological needs under drinking water's physical and physiological quality attributes. The consumers, therefore, aimed to maintain a healthy life with optimal drinking water consumption meeting their physiological needs by considering its physical and physiological qualities. For all these reasons, there was a significant demand for bottled water with higher physical quality and for purified tap water. In order to increase the water consumption satisfaction of the target group, therefore, it should expand the supply of bottled drinking water with high physical and

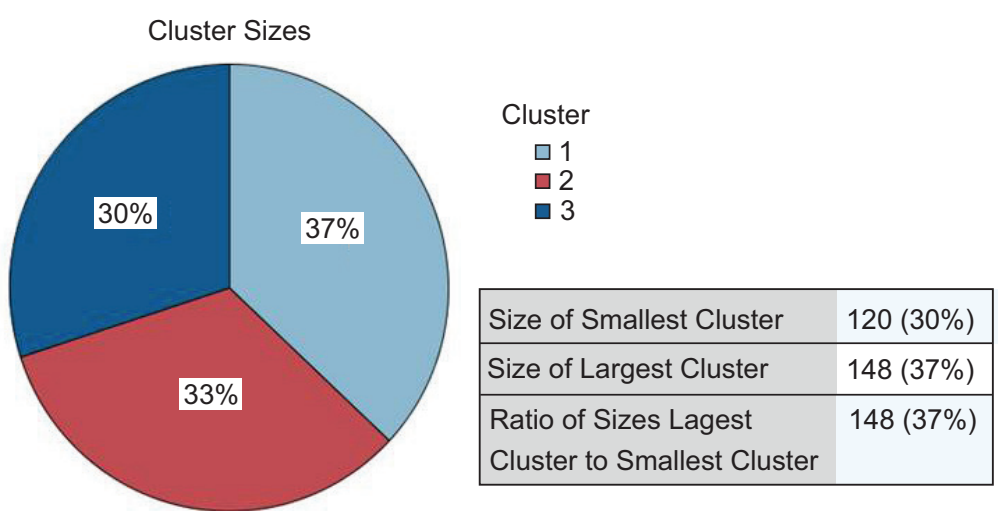

Figure 1. Cluster sizes and distributions. 
physiological qualities, and focus on the sales of water with these quality attributes by retailers.

On the other hand, the consumers dwelling in region II formed their drinking water consumption preference patterns by considering the reliance on tap water depending on the chemical quality of water. They took an approach that prioritizes the consumption of treated tap water by taking into account the chemical quality parameters of drinking water. If tap water's chemical quality analyses could be frequently made, and the precautions to maintain its standard quality attributes could be taken by the local governments, the consumers' water consumption satisfaction could be increased dramatically.

Similarly, the consumers living in region III developed their preference models with the basic advantage of fountain water depending on water's chemical quality. They attributed a bigger importance to water temperature being a physical quality parameter, and tried to supply drinking water from fountains providing spring water with the higher quality features by accounting for its chemical quality parameters. Being lower of its supply costs, therefore, and providing alternative selection possibility to their consumers according to chemical quality attributes could create the significant advantages to target consumers. Being exposed to various microbiological contaminants of the vehicles used during transportation and storage of fountain waters, however, could cause a vital threat. Delivering to the target consumer masses through various closed mains lines of fountain waters with high chemical quality attributes could considerably increase their drinking water consumption satisfaction.

\section{The results of the consumer cluster profiles}

Demographic and socioeconomic characteristics of three different homogenous consumer masses such as regions I, II, and III segmented by cluster analysis in Iğdır province are given in Table 4. The results of the frequency statistics showed that considering the gender demographics of the participants, men and women accounted for $49 \%$ and $51 \%$, respectively. While the distribution of the women and men in regions II and III were equally analyzed, the proportion of the women in region I was determined as $52 \%$.

When the consumers' occupational statutes in the research regions were analyzed, the ratios of the white-collars, housewives, workers, and students were determined as $29 \%, 20 \%, 16 \%$, and $3 \%$, respectively. While the white-collars predominate in all consumption regions, however, the housewives in region I, the workers in region II, and the students in regions II and III were of a bigger density.
On the other hand, the results of the descriptive statistics indicated that the average family size of the consumers residing in region I was 4.06 individuals and their average monthly food expenditure was $672.92 \mathrm{TL}$. They ranked the first, therefore, in terms of these results. Besides, the average age and education duration of the participants in region III reached the highest values with 37.71 and 11.21 years, respectively, average monthly income and total expenditure with 4697.01 and 2417.74 TL, respectively, and monthly water consumption amounted to $7.47 \mathrm{~L}$. Those dwelling in region II were at the lowest levels, however, in terms of all socioeconomic factors (Table 4).

\section{Conclusion}

The lack of substitution for water as a natural resource makes it an indispensable element for all living creatures throughout human history. In addition to the scarcity of water resources, increasing world population, industrialization, and intensive use of water in agriculture, as well as the negative effects of climate change on water resources make it difficult to access safer drinking water for people. Water consumption regimes, therefore, are regulated for crop and animal production in agricultural production, and alternation systems saving water are adopted. On the other hand, various saving and quality-enhancing measures have been implemented to make drinking water possible to people, and significant changes have occurred, therefore, in their attitudes and behaviors towards drinking water.

This study was planned to determine the factors affecting the attitude and behaviors of the consumers considering drinking water's quality characteristics toward its consumption, and to determine the consumption preferences of homogeneous consumer masses in Iğdır. In order to achieve this goal, the data obtained from faceto-face surveys with 400 consumers residing in Iğdır were used in FA and cluster analysis.

The research results indicated that the consumers with middle income, high food expenditure, and lower education levels under the lowest water consumption amount in region I tried to meet their physiological needs in a healthy way from bottled ready water and purified tap water by considering the microbiological and physical quality of drinking water. Similarly, it was determined that consumers in region II including mostly workers with water consumption amount at moderate levels under low income and food expenditure realized their drinking water consumption by considering the chemical quality parameters under the critical confidence interval values. It should be delivered sanitary drinking water to their residences by using the effective treatment systems at the tap water collection and distribution centers, 
therefore, and thus it could be increased their consumption satisfaction by qualified drinking water by accounting the chemical quality parameters in the region II.

On the other hand, it was understood that the consumers with white collars consuming high-leveled water under high income and food expenditure in region III tended to supply sources according to tap water's chemical and physical quality attributes, and thus they could also provide the quality and cost advantages. These consumers could constantly be exposed to various microbiological contaminations depending on various transportation and storage modes utilized for transporting fountain waters with high physical and chemical quality. The local and administrative authorities could provide a bigger impact on consumption satisfaction of drinking water with high chemical and physical quality attributes under reliable and healthy mains lines, and thus various risk factors could also minimize. The research results, at the same time, could provide important information to relevant policy makers, especially local authorities, drinking water supply providers, and contributors to the planning of future water resources and supply.

\section{Acknowledgement}

This work is supported by the Scientific Research Project Fund of Iğdır University under the project number 2019-FBE-A01.

\section{References}

Anonymous, 2015. T.C. Iğdır governorship, provincial directorate of environment and urbanization, Iğdır Province 2015 environmental status report. https://webdosya.csb.gov.tr/db/ced/editordosya/Igdir2015.pdf, (Accessed on May 20, 2021).

Arslan, C. and Mendeş, B., 2004. Studying liquid consumption and knowledge levels of male and female students in different departments of universities. Frrat University. Journal of Health Sciences 18(3): 163-172.

Cuvelier, N. and Bartell, S.M., 2021. Shrinkage estimation of longterm water ingestion rates. Journal of Exposure Science \& Environmental Epidemiology (2021): 1-9. https://doi. org/10.1038/s41370-021-00300-0

Doğan, B., 2008. Cluster analysis as a tool under the oversight of banks: An application for the Turkish Banking Sector (PhD thesis). Kadir Has University, Social Sciences Institute, Istanbul.

Domene, E. and Saurí, D., 2007. Urbanization and water consumption: influencing factors in the metropolitan region of Barcelona. Urban Studies 43(9): 1605-1612. http://doi. org/10.1080/00420980600749969

Dönderici, Z, Dönderici, A. and Başar, F., 2010. An investigation on physical and chemical quality of spring waters. Türk Hijyen ve Deneysel Biyoloji Dergisi 67(4): 167-172.
Doria, M.F., 2006. Bottled water versus tap water: understanding consumers' preferences. Journal of Water and Health 4(2): 271276. https://doi.org/10.2166/wh.2006.0023

DPT, 2007. 9th Development Plan. Use and Management of Land and Water Resources, DPT Ankara. https://www.sbb.gov.tr/ wp-content/uploads/2018/11/DokuzuncuKalk\%C4\%B1nmaPlan\%C4\%B1-20072013\%E2\%80\%8B.pdf, (Accessed on May 25, 2021).

Drugova, T., Curtis, K.C., Akhundjaov, S.B., 2020. Organic wheat products and consumer choice: a market segmentation analysis. British Food Journal 122(7): 2341-2358. https://doi.org/10.1108/ BFJ-08-2019-0626

Egbueri, J.C., Ezugwu, C.K., Ameh, P.D., Unigwe, C.O. and Ayejoto, D.A., 2020. Appraising drinking water quality in Ikem rural area based on chemo-metrics and multiple indexical methods. Environmental Monitoring and Assessment 192: 308. https://doi.org/10.1007/s10661-020-08277-3

Harwood, W.S., McLean, G.K., Ennis, J.M., Ennis, D.M. and Drake, M., 2020. Comparison of preference mapping with projective mapping for characterizing consumer perception of brewed black coffees. Journal of Sensory Studies 35: 1-10. https://doi.org/10.1111/joss.12563

İbrahim, A.S., Memon, F.A. and Butler, D., 2021. Seasonal variation of rainy and dry season per capita water consumption in Freetown City Sierra Leone. Water 13: 499-508. https://doi. org/10.3390/w13040499

Karagöz, Y., 2017. SPSS ve AMOS Uygulamalı Bilimsel Araştırma Yöntemleri". Nobel Akademik Yayıncılık ve Danışmanlık, Ankara.

Karpati, L. and Szakal, Z., 2009. Marketing characteristics of Tokaj wine specialties based on factor and cluster analyses. Applied studies in agribusiness and commerce-APSTRACT. Agroinform Publishing House, Budapest. http://doi.org/10.19041/ Apstract/2009/3-4/20

Kılıç, S., 2008. Küresel iklim değişikliği sürecinde su yönetimi İ.Ü. Siyasal Bilgiler Fakültesi Dergisi 39: 161-186.

Kurtuluş, K., 2004. Marketing Research. Extended 7th ed. Literature Publications, Istanbul.

Kusa, A., Zauskova, A. and Cabyova, L., 2020. Effect of marketing communication on consumer prefernces and purchasing decision. Journal of Interdisciplinary Research 1: 150-155.

Li, P. and Wu, J., 2019. Drinking water quality and public health. Exposure and Health 11: 73-79. http://doi.org/10.1007/s12403-019-00299-8

Liu, G., Zhang, Y., Knibbe, W.J., Feng, C., Liu, G.M. and Meer, W., 2017. Potential impacts of changing supply-water on drinking water distribution: a review. Water Research 116: 135-148. http://doi.org/10.1016/j.watres.2017.03.031

McGuinness, S.L., Toole, J., Barker, S.F., Forbes, A.B., Boving, T.B., Giriyan, A., et al. 2020. Household water storage management, hygiene practices, and associated drinking water quality in rural India. Environmental Science \& Technology 54(8): 4963-4973. https://doi.org/10.1021/acs.est.9b04818

Milton, A.H., Rahman, H., Smith, W., Shrestha, R. and Dear, K., 2006. Water consumption patterns in rural Bangladesh are we underestimating total arsenic load. Journal Water Health 4: 431439. https://doi.org/10.2166/wh.2006.0027 
Mukate, S., Wagh, V., Panaskar, D., Jacobs, J.A. and Sawant, A., 2019. Development of new integrated water quality index model to evaluate the drinking suitability of water. Ecological Indicators 101: 348-354. https://doi.org/10.1016/j.ecolind.2019.01.034.

Newbold, P., 1995. Statistics for business and economics. 4th ed. Prentice Hall International Editions. New Jersey.

Özdamar, K., 2004. Statistical data analysis with package programs 2 (Multivariate Analysis). 5th ed. Kaan Bookstore, Eskişehir.

Özgüler, H., 1997. Water, water resources and environmental issues: Meteorological Engineering. UCTEA Journal of the Chamber of Meteorology Engineers Issue 2: 57-63.

SPSS 20.0, 2020. IBM SPSS 20.0 base user's guide. 20th ed. Chicago, IL. ISBN 1-56827-370-3.

Suganthi, V., 2014. Analysis of bottled water consumption a study with special references to Pollachi Taluk. International Journal of Innovative Research Studies 3(7): 270-279.

Şahin, A.N., 2019. Current situation of organic markets in Izmir and Istanbul and development of the most preferred organic market design (PhD thesis). Ege University, Natural and Applied Science, Izmir.

Şekerler, A., 2008. Analysis of traffic accident data with clustering analysis method (MS thesis). Pamukkale University, Natural and Applied Science, Denizli. http://doi.org/10.5505/pajes.2016.81542

Şen, Z. and Altunkaynak, A., 2009. Fuzzy system modelling of drinking water consumption prediction. Expert Systems with Applications 36: 11745. https://doi.org/10.1016/j.eswa.2009.04.028

Tanellari, E., Bosch, D., Boyle, K, and Mykerezi, E., 2014. On consumers' attitudes and willingness to pay for improved drinking water quality and infrastructure. Water Resource Research 51(1): 47. https://doi.org/10.1002/2013WR014934.

Tekin, V.N., 2007. SPSS applied scientific marketing research. Seçkin Publishing, Ankara.

Topcu, Y., 2006. Brand competition and consumer behavior in dairy products: The Case of Erzurum province (PhD thesis). Ataturk Univ. Natural and Applied Science, Erzurum.
Topcu, Y. and Baran, D., 2017. Marketing strategies based on consumer preferences of Karnavas Mullberry Molasses with protected designation of origin (PDO). TURJAF 5(7): 822-831. http://doi.org/10.24925/turjaf.v5i7.822-831.1223

TUIK, 2020. Municipal Water Statistics, Turkey Statistical Institute. http://www.tuik.gov.tr/PreHaberBultenleri.do?id=30668, (Accessed on December 16, 2021).

Tümer, E.İ., Birinci A. and ve Yıldırım, Ç., 2011. Determination of factor affecting bottled water consumption: the case of Keçiören of Ankara province. Alinteri Journal of Agriculture Science 21(B): 11-19.

TURKSTAT, 2019. Address ased Population Registration System (ADNKS). https://adres.nvi.gov.tr/VatandasIslemleri/AdresSorgu, (Accessed on March 03, 2021).

UNESCO, 2019. WWAP (UNESCO World Water Assessment Program). United Nations World Water Development Report 2019: Leave Nobody Behind. UNESCO, Paris.

WWF, 2014. Dünya Doğayı Koruma Vakfı, Türkiye'nin Su Ayak İzi Raporu: Su, Üretim ve Uluslararası Ticaret İlişkisi. http://awsassets.wwftr.panda.org/download/su_ayak_izi_raporweb.pdf, (Accessed on May 21, 2021).

Yılmaz, M. and Peker, H., 2013. Su kaynaklarinin Türkiye açısından ekonomik-politik önemi ekseninde olasi bir tehlike: su savaşları. Çankırı Karatekin Üniversitesi İ̈BF Dergisi 3(1): 57-74. https:// dergipark.org.tr/tr/pub/ckuiibfd/issue/32891/365377, (Accessed on May 20, 2021).

Zlatanovic, L.J., Hoek, J.P. and Vreeburg, J.H.G., 2017. An experimental study on the influence of water stagnation and temperature change on water quality in a full-scale domestic drinking water system. Water Research 123: 761-772. http://doi. org/10.1016/j.watres.2017.07.019, (Accessed on May 28, 2021). 